\title{
SCIDiC
}

\author{
International Journal of Dentistry and Oral Science (IJDOS) \\ ISSN: 2377-8075
}

\section{Prevalence Of Ellis Class-II Restoration In Patients Above 16 Years Of Age-A Retrospective Study}

Research Article

\author{
Nivesh Krishna $\mathrm{R}^{1}$, Anjaneyulu $\mathrm{K}^{2 *}$, Arvind $\mathrm{S}^{3}$
}

${ }^{1}$ Saveetha Dental College and Hospitals, Saveetha Institute of Medical and Technical Sciences, Saveetha University, Chennai, India.

${ }^{2}$ Reader, Department of Conservative Dentistry, Saveetha Dental College and Hospitals, Saveetha Institute of Medical and Technical Sciences, Saveetha University, Chennai - 600077, India.

${ }^{3}$ Reader, Department of Orthodontics, Saveetha Dental College and Hospitals, Saveetha Institute Of Medical and Technical Science, Saveetha University, Chennai, India.

\section{Abstract}

Traumatic injuries of teeth are commonly seen among children and young adults. Such injuries are predominant in the upper anteriors. The uncomplicated fractures that affect only the enamel and dentin layer of the teeth without involving the pulp comes under Ellis class II type of traumatic injuries. These injuries may elicit as a loss of about $1 / 3$ rd crown structure with rough endings affecting the traumatised teeth. In other words, this level of injury includes crown fractures that extend through the enamel and dentin without pulpal involvement.The aim of this study is to elicit the prevalence of Ellis class-II restorations in patients above 16 years of age. The data collected from the records were 86000 and they were screened for patients with Ellis class II restoration. Patients above 16 years of age who underwent Ellis class-II restoration from June 2019 to March 2020 were chosen and divided into three age groups. Group 1 includes patients between 16-25 years of age, group 2 includes patients between 26-35 years of age and group 3 includes 36-70 years of age. The most predominant age group with the maximum number of restorations was estimated statistically. From the study it can be estimated that among 284 patients who have undergone Ellis class-II restoration, the number of male patients were 189 and the number of female patients were 95. The predominant gender was males with the highest frequency. Considering the age groups, group-1(16-25 years) includes 123 patients, group-2 (26-35 years) includes 79 patients and group-3 (36-70 years) includes 82 patients. The predominant age group with the highest prevalence of Ellis class-II restoration is 16-25 years i.e. group-1. From the statistical test, it can be estimated that figure-I indicates the distribution of study population based on age wherein $43 \%$ of patients belonged to group-1 with highest frequency and $27 \%$ of patients belonged to group-3 with the lowest frequency. Figure-II indicates the distribution of the study population based on gender, wherein $67 \%$ of the patients were males with the highest frequency and $33 \%$ were females with the lowest frequency. A chi-square association test(chi-square- 9.154;df-1;p-0.037 $(\mathrm{p}<0.05)$ gives a statistically significant association between gender, age group and the presence of Ellis class-II restoration.

Keywords: Anterior Tooth; Composite Resin Restoration; Dentin; Ellis Fractures; Enamel; Fragment Reattachment.

\section{Introduction}

The important criteria of a beautiful smile lies in the alignment, colour of the teeth and the harmony of the lips. This is attributed to the beauty of the face [1]. Factors such as bruxism, dental injuries, erosions and abrasions can wear out the anterior teeth's natural harmony. Recent day innovations in adhesive dentistry have uplifted the utilization of aesthetic restorative procedures as alternatives of anterior teeth rehabilitation. Several techniques have been advocated for the restoration of fractured teeth, such as resin, ceramic or steel crowns, orthodontic bands, and resin composite restorations with and without pins There are two types of techniques of using ceramic materials for restoring the esthetics of anterior teeth. They are the direct and indirect techniques $[2,3]$. The indirect technique is the perfect choice for re-anatomization of the teeth. It also represents better longevity and color

\author{
*Corresponding Author: \\ Anjaneyulu K, \\ Reader, Department of Conservative Dentistry, Saveetha Dental College and Hospitals, Saveetha Institute of Medical and Technical Sciences, Saveetha University, Chennai - 600077, \\ India. \\ Tel: 8056135807 \\ E-mail: kanjaneyulu.sdc@saveetha.com \\ Received: April 28, 2021 \\ Accepted: July 09, 2021 \\ Published: July 30, 2021
}

Citation: Nivesh Krishna R, Anjaneyulu K, Arvind S. Prevalence Of Ellis Class-II Restoration In Patients Above 16 Years Of Age-A Retrospective Study Int J Dentistry Oral Sci. 2021;8(7):3568-3572. doi: http://dx.doi.org/10.19070/2377-8075-21000730

Copyright: Anjaneyulu $\mathbf{K}^{\circ}$ 2021. This is an open-access article distributed under the terms of the Creative Commons Attribution License, which permits unrestricted use, distribution and reproduction in any medium, provided the original author and source are credited. 
maintenance when compared to the direct technique. Indirect technique comprises construction of the restoration outside the oral cavity on a die. Then, it is placed and cemented on the prepared cavity while it's solidified or set. However, this technique requires a greater number of clinical sessions and cost compared to direct techniques. Direct technique comprises application of the material into a prepared cavity while it's in plastic phase for construction of restoration intra-orally. Condensation pressure may be applied. There is good longevity and it is done at a low cost compared to indirect technique $[4,5]$. There is a success rate of $85 \%$. Even after years in function, the restorations require only repairs or polishing $[6,7]$.

Anterior crown fractures are common forms of injuries that mainly affect children and adolescents [8]. Uncomplicated crown fracture to the permanent teeth has an excellent effect not only on the patient's appearance, but also on function and speech. Esthetic restoration of a broken incisal edge of maxillary central incisors is a technique sensitive procedure. Its success depends on the operator's skills and also the operator's problem solving approach. The integrity of the broken or fractured segment is directly proportional to the intensity of difficulty of aesthetic restoration [9]. Several studies have been demonstrated to elicit the prevalence and associated risk factors of crown fractures [10, 11]. Since the anterior teeth fracture is the most frequent type of injury among adolescents and young aged persons, there is a demanding need for an aesthetic restoration. Upto $45 \%$ of the young population has been affected due to these traumatic fractures. Uncomplicated tooth fractures consist of fracture lines involving the enamel and dentin of the teeth. However, the complicated fractures include the fracture line extending upto the pulp. According to Ellis and Davey classification, fracture of enamel and dentin falls under class I and class II respectively and fracture of dental pulp falls under class III type of fractures. These coronal attributes are managed by the extent of the crack line, its pattern and their restorability. The restorative material that is used in the aesthetic procedure should be in such a way that it matches the natural harmony of the tooth. The material should also have a good mechanical strength and good durability so that it doesn't break whilst mastication. This is the most important factor that has to be considered while doing the esthetic procedure. Some of the factors to be considered during the procedure are isolation of the fractured tooth or teeth and preparation and contouring of the bevel. Isolating the tooth will avoid contaminants of the tooth from getting into the oral cavity, clear view, reduce salivation of the patient. Bevelling will elicit a better marginal integrity of the restoration and its durability. It will also enhance the longevity of the restoration. Finishing and polishing of the restored tooth or teeth will elicit a perfect aesthetic restorative treatment [12-14].

Despite the recent day modifications, the utilisation of the composite resins for the restoration of the anterior tooth fractures pose a lot of drawbacks. Some of the drawbacks include polymerisation shrinkage upon curing, discoloration over an extended period of time and sometimes, may not fully restore the fracture of the intact tooth. These setbacks can lead to limited longevity for big anterior composite restorations. More importantly, there is a lack of well-controlled, independent, long-term, and adequately-powered clinical trials on the restoration of fractured anterior teeth with modern composites and adhesives [15]. Previously our team had conducted numerous clinical trials [16-18], in vitro studies [19-21] and surveyed [22-24] and reviewed [25-30] various as- pects of endodontics and conservative dentistry over the past five years. Now we are focusing on retrospective studies, the idea for which has stemmed from the current interest in our community. The aim of the study is to estimate the prevalence of Ellis class-II restoration in patients above 16 years of age and discuss various treatment modalities. The aim of the study is to estimate the prevalence of Ellis class-II restoration in patients above 16 years of age and discuss various treatment modalities.

\section{Materials And Methods}

\section{Sampling}

Non-probability sampling was collected from June 2019 to March 2020. The case sheets of the patients above 16 years of age who had reported to Saveetha Dental college for the treatment of gingival enlargement were reviewed. The external validity was good, as it is generalisable among patients of the same ethnic origins within the state and country.

\section{Ethical approval}

Ethical approval was obtained from the Institutional Ethical Committee and scientific review board [SRB] of Saveetha Dental College. SDC/SIHEC/2020/DIAS/DATA/0619-0320

\section{Data Collection}

The data collected from june 2019 to march 2020 after screening 86000 records and study subjects were selected. Among the 86000 records, patients with Ellis class I restoration were chosen. The data was obtained by reviewing patients who reported to saveetha dental college. The data collected included parameters such as patient's name, age, gender, diagnosis and the type of treatment done. The sample size was 284 patients. Patient data obtained was cross verified with treatment photographs. The data was collected and tabulated in the excel sheet and imported to spss software for statistical analysis.

\section{Statistical Analysis}

The data was imported to spss software by IBM version 25.0 for Windows OS in which the output variables were defined. The independent variables were age and gender whereas the dependent variables were the type of restoration done and the statistical mean value obtained. The statistical test used was the chi-square test to establish the results.

\section{Methodology}

The study patients above 16 years of age restored with Ellis classII were collected and divided into three groups based on their age. Group 1 includes patients between 16-25 years of age, group 2 includes patients between 26-35 years of age and group 3 includes 36-70 years of age. The most predominant age group and the most predominant gender with the maximum number of restorations was estimated statistically.

\section{Results}

From the study it can be estimated that among 284 patients who 
Figure 1: Pie chart showing the distribution of the patients across the three age groups.

Pink color denotes group 1 (16-25 years), red color denotes group 2 (26-35 years), orange color denotes group 3 (36-70 years). Among all the patients who underwent treatment for Ellis class- II restoration, patients belonging to group 1 were found to be predominant $(43.31 \%)$, followed by group $3(28.87 \%)$ and group $2(27.82 \%)$.

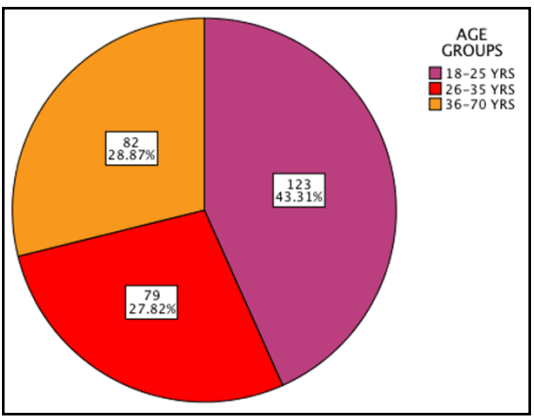

Figure 2: Pie chart showing the distribution of the patients based on gender. Males are denoted by yellow color and females are denoted by black color. From the study, it can be estimated that among 284 patients who have undergone Ellis class-II restoration, the number of male patients were $(66.55 \%)$ and the number of female patients were $(33.45 \%)$. The predominant gender was males with the highest frequency.

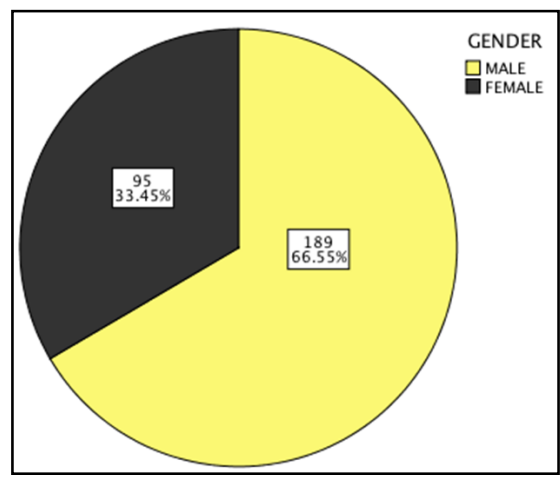

Figure 3: Bar graph showing the association between age group and gender prevalence of Ellis class-II restoration. $\mathrm{X}$ axis represents the age group and $\mathrm{Y}$ axis represents the number of patients. Males (yellow) had a higher number of Ellis classII restoration than females (black) in group 1(16-25 years) and group 2(26-35 years) whereas in group 3 (36-70 years), female predominance was observed. In group 1 the number of males $(36.21 \%)$ were significantly higher than females(7.04\%). In group 2 the number of males $(19.37 \%)$ were significantly higher than females $(8.45 \%)$ whereas in group 3 the number of females(17.96\%) were significantly higher than males $(10.92 \%)$. (Chi-square value- 9.154 , $p$ value- 0.03 ( $p<0.05)$; hence statistically significant)

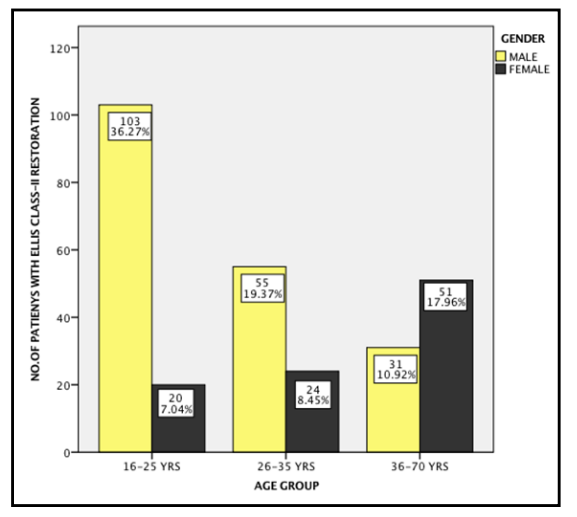

have undergone Ellis class-II restoration, the number of male patients were 189 and the number of female patients were 95. The predominant gender was males with the highest frequency. Considering the age groups, group-1(16-25 years) includes 123 patients, group-2 (26-35 years) includes 79 patients and group-3 (36-70 years) includes 82 patients. The predominant age group with the highest prevalence of Ellis class-II restoration is 16-25 years i.e. group-1. From the statistical test, it can be estimated that figure-I indicates the distribution of study population based on age wherein $43 \%$ of patients belonged to group-1 with highest frequency and $27 \%$ of patients belonged to group-3 with a lowest frequency. Figure-II indicates the distribution of study population based on gender wherein $67 \%$ of the patients were males with the highest frequency and 33\% were females with the lowest frequency. A chi-square association test (chi-square - 9.154; $\mathrm{df}^{-1} ; \mathrm{p}$ $0.037(\mathrm{p}<0.05)$ gives a statistically significant association between gender, age group and the presence of Ellis class-II restoration.

\section{Discussion}

The treatment plan of using direct composite resin restorations for aesthetic restorative procedures is elicited due to their excel- 
lent properties and performance. For a better treatment prognosis, dental professionals should consider the type and shade of the composite resin as well as the hybridisation of the tooth structure whether it is elicited as self etching or enamel etching or no etching technique [31]. A study by Jour et al showed the high success rate for the direct method of composite resin restorations, provided they follow the principles of the restoration. There is about an $80-90 \%$ success rate for Class I,II and III restorations even after a period of 10 years. There is a psychological impact created on both the parents and in children due to the traumatic injuries. Anterior tooth fracture management still poses a great challenge to the operator from a functional as well as an aesthetic perspective. Treatment phases may alter due to the differences in age, socio-economic status and the intraoral status of the patient. Among different types of tooth injuries, Ellis Class II fracture is maximum in number with a percentage of thirty. Class II fractures are predominant in accidents, falls and sports injuries [32].

Following Ellis Class II fracture, the next most commonly occurring type of fracture is Ellis Class I which is the fracture of enamel only. A study by Zerfowski et al(1998) demonstrated that the majority of crown fractures in permanent dentition had a percentage range between $26-76 \%$ while crown root or complicated fractures account for about $0.3-5 \%$ only [33]. Law in his study, elicited the fact that there were $75 \%$ of fractured teeth occurring between the ages of 7-11 years and 40\% were of enamel fractures and 60\% included dentinal fractures as well. This shows the prevalence of Ellis class II fracture, which is in correlation with this study [34].

Class IV type of tooth injury or the root fracture cases is minimal as $1 \%$. Type VII tooth fracture, in other words, displacement of the tooth with or without the crown or root fracture is also commonly seen in sports injuries whereas Ellis class VIII fractures are seen in fall injuries.A study by Rajab L.D.(2000) demonstrated that the prevalence of these injuries occur in 15-20 years of age group. Boys were more affected than girls which indicates a male predominance. Therefore, it correlates with this study [35]. Falls were the most predominant type of injuries and the most commonly affected teeth were maxillary central incisors. The peak incidence of injury was 10-12 years of age group [36]. Study by Gojanur S et al., (2015) elicited the prevalence of traumatic injuries of the anterior teeth among 14 children of age group 5-8 years [37]. According to Ellis and Davey's classification, it was observed that Ellis class IX type of fracture was predominant followed by Ellis class I and class II fractures, wherein the most common affected teeth were maxillary central incisors followed by lateral incisors. According to this study, the most common cause of trauma was due to falls $(7.1 \%)$ followed by bicycle accidents $(11.1 \%)$, collisions $(8.9 \%)$, violence $(6.7 \%)$ and bike accidents $(2.2 \%)$. The dentist plays a significant role in the management of traumatic injuries such that every possible way of saving a traumatised tooth must be taken into consideration. The remarkable modifications of the adhesive systems and resin bonded composites have enhanced the prognosis of the restorative treatment to the next level. However, these treatments are implemented only when the affected tooth is intact [38].

\section{Limitations}

The data may have discrepancies since it is limited to Ellis classII fracture confined to a specific geographic location. The study does not include age groups less than 16 years.

\section{Future scope}

The study gives a broad idea on Ellis classification of traumatic injuries and management of uncomplicated fractures in an effective way.

\section{Conclusion}

Awareness on tooth fractures, its complications, and the need for treatment should be insisted on among parents and young adults. Oral screening must be performed by conducting camps in order to diagnose these fractures at the earliest so that necessary steps can be taken to save the remaining tooth structures. Patients must be instructed on frequent reviews every 6 months to 1 year to check the quality of restoration and prevent restoration failure.

\section{Acknowledgement}

I sincerely express my gratitude and acknowledgement to Dr.Anjaneyulu and Dr.Arvind Sivakumar and Dean and management for their support and also thank the Research and IT department of Saveetha dental college (SIMATS) for their affable assistance in analyzing the data.

\section{References}

[1]. Lecocq G, Trung LT. Smile esthetics: Calculated beauty?. Int. Orthod. 2014 Jun 1;12(2):149-70.

[2]. PONTONS-MELO JC, Pizzatto E, Furuse AY, Mondelli J. A conservative approach for restoring anterior guidance: a case report. J Esthet Restor Dent. 2012 Jun;24(3):171-82.

[3]. Schirra C. Loss of vertical dimension: Extensive therapy in dentitions with erosion and abrasion. A treatment strategy for the dental practitioner. Quintessence Int. 2013 Nov 1;44(10) : 733-740.

[4]. Ardu S, Duc O, Krejci I, Perroud R. Amelogenesis imperfecta: a conservative and progressive adhesive treatment concept. Oper Dent. 2013 MayJun;38(3):235-41.Pubmed PMID: 23116390.

[5]. Pontons-Melo JC, Furuse AY, Mondelli J. A direct composite resin stratification technique for restoration of the smile. Quintessence international. 2011 Mar 1;42(3) : 205-211.

[6]. Humel MM, Takahashi JM, Paulillo LA, Mesquita MF, Martins LR. Direct restorative treatment of anterior weared teeth after re-establishment of occlusal vertical dimension: a case report. Gerodontology. 2012 Dec;29(4):299307.Pubmed PMID: 23167726.

[7]. Samadi Firoza, J.N Jaiswal, Pandey Sunil, Bansal Neha, F Samadi. Restoration of fractured anterior teeth using thermoformed templates - A Case Report. journal of- dentofacialsciences.com 2012;1:25-28.Available from:

[8]. Rajavardhan K, Sankar AS, Shaik TA, Kumar N. A novel technique in restoring fractured anterior teeth. J Clin Diagn Res. 2014 Feb;8(2):244-245.

[9]. Hasan A, Shahid O. Esthetic restorations, the putty matrix technique. J Dow Univ Health Sci. 2013 Sep 3;7(3):122-5.

[10]. Hamilton FA, Hill FJ, Holloway PJ. An investigation of dento-alveolar trau$\mathrm{ma}$ and its treatment in an adolescent population. Part 2: Dentists' knowledge of management methods and their perceptions of barriers to providing care. Br Dent J. 1997 Feb 22;182(4):129-33.Pubmed PMID: 9061998.

[11]. Marcenes W, al Beiruti N, Tayfour D, Issa S. Epidemiology of traumatic injuries to the permanent incisors of 9-12-year-old schoolchildren in Damascus, Syria. Endod Dent Traumatol. 1999 Jun;15(3):117-23.Pubmed PMID: 10530154.

[12]. Marcenes W, Alessi ON, Traebert J. Causes and prevalence of traumatic injuries to the permanent incisors of school children aged 12 years in Jaragua do Sul, Brazil. Int Dent J. 2000 Apr;50(2):87-92.Pubmed PMID: 10945187.

[13]. Marcenes W, Murray S. Social deprivation and traumatic dental injuries among 14-year-old schoolchildren in Newham, London. Dent Traumatol. 2001 Feb;17(1):17-21.Pubmed PMID: 11475766.

[14]. Marcenes W, Zabot NE, Traebert J. Socio-economic correlates of traumatic injuries to the permanent incisors in schoolchildren aged 12 years in Blu- 
menau, Brazil. Dent Traumatol. 2001 Oct;17(5):222-6.Pubmed PMID: 11678542 .

[15]. Stockwell AJ. Incidence of dental trauma in the Western Australian school dental service. Community Dent. Oral Epidemiol. 1988 Oct;16(5):294-8.

[16]. Ramamoorthi S, Nivedhitha MS, Divyanand MJ. Comparative evaluation of postoperative pain after using endodontic needle and EndoActivator during root canal irrigation: A randomised controlled trial. Aust Endod J. 2015 Aug;41(2):78-87.Pubmed PMID: 25195661.

[17]. Hussainy SN, Nasim I, Thomas T, Ranjan M. Clinical performance of resinmodified glass ionomer cement, flowable composite, and polyacid-modified resin composite in noncarious cervical lesions: One-year follow-up. J Conserv Dent. 2018 Sep-Oct;21(5):510-515.Pubmed PMID: 30294112.

[18]. Janani K, Palanivelu A, Sandhya R. Diagnostic accuracy of dental pulse oximeter with customized sensor holder, thermal test and electric pulp test for the evaluation of pulp vitality: an in vivo study. Braz. Dent. Sci. 2020 Jan 31;23(1):8.

[19]. Ramanathan S, Solete P. Cone-beam Computed Tomography Evaluation of Root Canal Preparation using Various Rotary Instruments: An in vitro Study. J Contemp Dent Pract. 2015 Nov 1;16(11):869-72.

[20]. Nandakumar M, Nasim I. Comparative evaluation of grape seed and cranberry extracts in preventing enamel erosion: An optical emission spectrometric analysis. J Conserv Dent. 2018 Sep-Oct;21(5):516-520.Pubmed PMID: 30294113

[21]. Teja KV, Ramesh S, Priya V. Regulation of matrix metalloproteinase-3 gene expression in inflammation: A molecular study. J. Conserv. Dent. 2018 Nov;21(6):592.

[22]. Rajendran R, Kunjusankaran RN, Sandhya R, Anilkumar A, Santhosh R, Patil SR. Comparative evaluation of remineralizing potential of a paste containing bioactive glass and a topical cream containing casein phosphopeptide-amorphous calcium phosphate: An in vitro study. Pesqui Bras Odontopediatria Clin Integr. 2019 Oct 10;19:1-10.

[23]. Manohar MP, Sharma S. A survey of the knowledge, attitude, and awareness about the principal choice of intracanal medicaments among the general dental practitioners and nonendodontic specialists. Indian J Dent Res. 2018 Nov-Dec;29(6):716-720.Pubmed PMID: 30588997.

[24]. Jose J, Subbaiyan H. Different treatment modalities followed by dental practitioners for Ellis class 2 fracture-A questionnaire-based survey. Open Dent. J. 2020 Feb 18;14(1):59-65.

[25]. Teja KV, Ramesh S. Shape optimal and clean more. Saudi Endod. J. 2019 Sep 1;9(3):235.
[26]. Noor SS. Chlorhexidine: Its properties and effects. Res J Pharm Technol. 2016;9(10):1755-60.

[27]. Kumar D, Antony S. Calcified canal and negotiation-A review. Res J Pharm Technol. 2018;11(8):3727-30.

[28]. Ravinthar K. Recent advancements in laminates and veneers in dentistry. Res J Pharm Technol. 2018;11(2):785-7.

[29]. Rajakeerthi R, Nivedhitha MS. Use of cone beam computed tomography to identify the morphology of maxillary and mandibular premolars in Chennai population. Braz. Dent. Sci. 2019 Jan 31;22(1):55-62.

[30]. Siddique R, Sureshbabu NM, Somasundaram J, Jacob B, Selvam D. Qualitative and quantitative analysis of precipitate formation following interaction of chlorhexidine with sodium hypochlorite, neem, and tulsi. J Conserv Dent. 2019 Jan-Feb;22(1):40-47.Pubmed PMID: 30820081.

[31]. Blackham JT, Vandewalle KS, Lien W. Properties of hybrid resin composite systems containing prepolymerized filler particles. Oper Dent. 2009 NovDec;34(6):697-702.Pubmed PMID: 19953779.

[32]. JOUR Kole, Daliya Dholey, Kanti Sen, Sukanta 2019/02/02 2429 Prevalence of permanent anterior teeth fracture among young children's aged 8-14 years according to Ellis and Davey's classification- An epidemiological study 18 IOSR Journal of Dental and Medical Sciences.

[33]. Zerfowski M, Bremerich A. Facial trauma in children and adolescents. Clin. Oral Investig. 1998 Nov;2(3):120-4.

[34]. LAW DB. Prevention and treatment of traumatized permanent anterior teeth. Dent Clin NAm 1973; 66:431-50.

[35]. Andreasen JO, Ravn JJ. Epidemiology of traumatic dental injuries to primary and permanent teeth in a Danish population sample. Int J Oral Surg. 1972;1(5):235-9.Pubmed PMID: 4146883.

[36]. Rajab LD. Traumatic dental injuries in children presenting for treatment at the Department of Pediatric Dentistry, Faculty of Dentistry, University of Jordan, 1997-2000. Dent Traumatol. 2003 Feb;16(1):6-11.Pubmed PMID: 12656848.

[37]. Gojanur S, Yeluri R, Munshi AK. Prevalence and Etiology of Traumatic Injuries to the Anterior Teeth among 5 to 8 Years Old School Children in Mathura City, India: An Epidemiological Study. Int J Clin Pediatr Dent. 2015 Sep-Dec;8(3):172-5.Pubmed PMID: 26628850.

[38]. Simonsen RJ. Traumatic fracture restoration: an alternative use of the acid etch technique. Quintessence Int Dent Dig. 1979 Feb;10(2):15-22.Pubmed PMID: 399008. 